\title{
Enunciación
}

http://revistas.udistrital.edu.co/ojs/index.php/enunc

\section{La economía política clásica y la cibercultura. El mercado del chat como intercambio de bienes y servicios}

\section{The classic political economy and the cyberculture. The chat market as exchange of goods and services}

\author{
Luz Marilyn Ortiz Sánchez ${ }^{1}$
}

\begin{abstract}
Para citar este artículo: Ortiz, L. M. (2015). La economía política clásica y la cibercultura. El mercado del chat como intercambio de bienes y servicios. Enunciación, 20(1), pp. 78-93.
\end{abstract}

Recibido: 26-abril-2015 / Aprobado: 30- mayo-2015

\section{Resumen}

En este artículo se pretende reflexionar sobre la propiedad de los medios de comunicación y los medios de producción, partiendo de la relación entre los usuarios electrónicos y lo que implica la propiedad real virtual, en el entendido de que las relaciones de producción en la nube y en la interacción electrónica traen consigo una serie de implicaciones epistemológicas caracterizadas por la virtualidad, cuyo mercado y proceso de interacción es la red. Estos aspectos permiten establecer una relación directa con la investigación sobre el chat en el mundo de la cibercultura y, en concreto, del chat como lenguaje emergente, ya que la relación entre el lenguaje y la cultura, lenguaje y conocimiento $y$, sobre todo, lenguaje y economía, visto desde los sistemas de producción, son una forma entender los productos simbólicos de las sociedades actuales.

Palabras clave: cadena de valor, cibercultura, economía, productos simbólicos, red.

\begin{abstract}
This article is an important part of the doctoral thesis topics "Configuration of the semiotics of the chat: a multimodal view", in which the reflection on the media and the means of production ownership is proposed, from the relationship between the users of electronic devices and the virtual - real ownership consequences, bearing in mind that the cloud production relation and the electronic interaction bring about a series of epistemological implications characterized by the virtuality whose market and process of interaction is the web. This interaction allows a straight relationship with the research about the chat in a cyberculture world and specifically the chat as an emergent language, since the relationship between the language and the culture, the language and the knowledge and the most relevant one, the language and the economy, from a production system point of view, are a way to understand the symbolic products of the current society.
\end{abstract}

Keywords: Value chain, cyberculture, economy, symbolic products, network.

1 Docente investigadora de la Universidad Distrital Francisco José de Caldas. Magíster en Lingüística Hispánica, candidata a doctora en Lenguaje y Cultura. Correos electrónicos: Imortiz@udistrital.edu.co; luzmarilynortiz@gmail.com 


\section{INTRODUCCIÓN}

El fetichismo de las comodidades continúa siendo aleccionador en el siglo XXI, pues por lo visto estamos siendo, como nunca antes, dominados por una cultura del consumidor.

Featherstone.

El propósito de este artículo es mostrar una perspectiva conceptual de las mediaciones simbólicas, del uso de los lenguajes multimodales en el chat y los efectos del mercado de las TIC en la cadena de valor, que dé cuenta de las nuevas formas de producción del mercado global, en la dimensión del capital cognitivo y en la construcción de sujetos y subjetividades en la producción de identidades corpóreas.

Desde la cibercultura, es importante reconocer el papel esencial del antagonismo social dentro de la web, en un proceso de enfrentamiento de posiciones políticas y abierto conflicto de intereses. Lo que genera una serie de propuestas comunicativas, que están reflejadas en las expresiones multimodales ${ }^{3}$ como parte de la cartografía sociosemiótica de la red, en la que la producción de imágenes, emoticonos, memes, etc., muestran en el carácter cultural de la comunicación digital un nuevo lenguaje cargado de estrategias de mercadeo, que construye otras formas innovadoras de comunicación y de intercambio sociocultural, económico y político.

Esta consideración afecta tanto el carácter del conocimiento como de la conducta humana, lo que determina un fenómeno de catálisis, de cambio, de transformación de los sujetos y por ende de la cultura; bien lo referencia Bell al afirmar que:

3 Recursos semióticos que evidencian la presencia de lenguajes híbridos multimediales, donde predomina el signo como unidad semiótica (símbolo, indicio, señal, icono, signo), que implican sincretismo, totalidad.
La sociedad post-industrial representa un cambio creciente y no planeado del carácter de la sociedad, como resultado de la lógica de la organización socioeconómica, y un cambio en el carácter del conocimiento. Llegando a cierto punto, los grupos sociales más importantes toman conciencia de la transformación social subyacente y tienen que decidir, políticamente, si aceptan el giro, lo aceleran, lo impiden o cambian su dirección (1976, p. 99).

Este entorno ciberespacial como fenómeno social se ha convertido en parte de la cultura, como Lévy (2007, p. 6) afirma: "Es imposible separar lo humano de su entorno material ni de los signos e imágenes a través de los cuales dan sentido a su vida y a su mundo". Hoy es imposible separar las implicaciones sociales que el ciberespacio da a las significaciones culturales.

De ahí que las formas simbólicas sean intencionales y convencionales, pues son el resultado del ser y hacer creador del sujeto, como pulsión creativa para producir, interpretar y proyectar el mundo como elemento transformador de la cultura. Este juego de relaciones o de poderes, que manejan el control de dominios, en cuanto a marcas registros y patentes, son formas simbólicas intencionales cuya expresión de unos sujetos, instituciones o poderes se orientan al colectivo persiguiendo determinados fines u objetivos que son convalidados o no, dependiendo de la construcción, uso o interpretación simbólica por parte del sujeto que la recibe. Bien lo planteaba Saussure (1985) en cuanto a que lo arbitrario del signo lingüístico nos permite comprender por qué el hecho social es el único que puede crear un sistema lingüístico, ya que la colectividad es quien puede establecer valores que están en el uso y en el consenso general: "La colectividad es necesaria para establecer valores cuya única razón de ser esta en el uso y en el consenso general; el individuo por si solo es incapaz de fijar ninguno" (p. 140); es "la totalidad solidaria" la que imprime valor. 
El valor considerado en su aspecto conceptual es un elemento de significación dado por la cultura; los signos no representan ideas dadas de antemano, sino el valor adquirido en el sistema, ya que no se definen por su contenido, sino por su relación con los demás en esa cadena de múltiples significados; por tanto, la significación no existiría si el signo no tuviera un valor determinado, dado por las relaciones con otros valores similares. El signo lingüístico, y en general todo signo, es valor, lo que hace que forme una oposición, ya que se convierte en un sistema de valores que, en la medida en que adquieren igual valor, permite el intercambio.

Así las cosas, si el lenguaje está destinado al intercambio desde la economía y la cultura, podemos centrarnos en un lugar común desde la cadena de valor como generadora de tendencias en cuanto a la producción, distribución, circulación y consumo de signos de valor y de sentido social, que configura la sociedad global actual como consumidora; lo que convierte, desde el marco semiótico, cultural y económico, el poder del lenguaje en acción, y genera a su vez una política de intercambio desde la información, el conocimiento y la comunicación.

Aquí, la proliferación de información y de conocimientos forma un capital simbólico que se transforma en una acumulación de capital fundamentalmente idealizado, pues la mercancía muta de material a inmaterial y se convierte en un "capital cognitivo" o "forma de conocimiento" (Moulier, Corsani y Lazzarato, 2004, p. 104) de la producción en red como producto de la inteligencia colectiva, cuyo valor son las ideas.

Esta producción de ideas depende en gran medida de la capacidad de creación y de innovación de los sujetos que hacen parte de este mercado cognitivo, donde no solo se juega con los cuerpos, sino que hay mil variantes de uso para modular los deseos y las pasiones. Estos bienes informacionales que se encuentran enmarcados en la esfera de lo semiótico incorporan el lenguaje como rutina común de nuevos usos, de otras creaciones y de otras apropiaciones, dándole a este un peso específico como valor de uso. Se venden las imágenes, los estilos de vida, los símbolos, las identidades; este mercado virtual es altamente diferenciado, ya que no se contrata directamente, ni se trabaja de manera presencial en la fábrica o en la oficina, pues estos espacios han mutado de lo físico-material a lo cognitivo-virtual.

\section{DEL CAPITALISMO CLÁSICO AL CAPITALISMO COGNITIVO}

El paso directo del capitalismo clásico al capitalismo cognitivo establece otro tipo de relaciones socioculturales, ya que transforma el conocimiento colectivo virtualizado en una cadena de bienes inmateriales, cuya producción en red hace que la cooperación y la construcción de saberes y sus resultados, es decir, el producto, se conviertan a partir de su producción y distribución en un bien común que pertenece al mundo de la cibercultura:

En este sentido, la economía del conocimiento es una economía de la velocidad: los valores no son stocks que se conservan con el tiempo, sino que estos decrecen con el aumento de la velocidad de los procesos... Es decir, conforme van cayendo las barreras que limitan su acceso, deviene patrimonio común para todos los concurrentes y todos los usuarios potenciales (Moulier et al., 2004, p. 103).

Esto significa que, para alcanzar la mayor difusión posible, es necesario acortar el tiempo y las distancias, ya que el valor otorgado a la "idea" depende del mercado instantáneo y de su divulgación efectiva en ese mercado global de bienes inmateriales. Aquí, la cadena de valor, en tanto bienes, intercambios y servicios, obedece a las manifestaciones semióticas cuyas formas de representar el mundo, con su poderoso dispositivo de producción de sentidos (internet), 
está en permanente marcha en continuo y acelerado cambio.

Desde esta mirada, el lenguaje ya no representa el mundo y la realidad objetiva; por el contrario, su poder constituyente permite al sujeto de acción, a través de los lenguajes, construir, modificar, intervenir y afectar el mundo y los mundos posibles (Cárdenas, 2001), gracias no solo a las cadenas significantes, sino a las relaciones de estas con otros objetos y sujetos en una red doble: intersubjetiva e interobjetiva, en la que se tejen redes de sentidos entre múltiples sujetos y objetos.

Entonces, desde el capitalismo cognitivo, esta concepción de producción teje una sociedad cuya medida se da en la globalización actual y cuya tendencia es la renovación de un proceso histórico de acumulación de capital, en el cual existía un obrero, un horario, un salario, un empleo en un espacio cerrado, que daba como resultado a un sujeto productor y acumulador de riqueza. Para dar paso a una concepción de producción en red, cuyos bienes son inmateriales, los empleos flexibles y flotantes, las oficinas abiertas en espacios simbólicos, donde el mundo virtual en sí es la fábrica o empresa de producción. No hay tiempo, espacio, ni fronteras; el trabajador es esporádico, invisible, acorpóreo; el pago o valor salarial se le reconoce por el resultado, mas no por el proceso: es lo que Moulier et al. (2004) denominan "obreros del conocimiento", es decir, se convierte la idea en mercado, en capital simbólico, en el cual:

El proceso de transformación de conocimiento en valor no es, de esta suerte, lineal y estable en el tiempo. Al contrario, implica inestabilidad, puntos de discontinuidad, catástrofes, una multiplicidad de caminos posibles. Es justamente cuando nos situamos en un punto de vista postfordista cuando los obstáculos reencontrados por la valorización del conocimiento ponen al descubierto espacios de crisis (Moulier et al., 2004, p. 101).
Estas nuevas dinámicas globales de trabajo configuran un tejido social cuyos hilos están entretejidos en la red y son conductores de deseos, afectos y pasiones, es decir, de lo que espera la sociedad global de consumo; la modulación de la mercancía hace que el deseo del consumidor aflore y prolifere en las redes sociales virtuales; estos valores determinantes en la promoción de subjetividades e intercambios de identidades hacen que allí se encuentre a la venta toda clase de mundos posibles que les permiten a los cibernautas, en la construcción de sus subjetividades, edificar sus estilos o modos de vida.

Así, el valor estético, el valor del cuerpo y lo corpóreo se convierten en un elemento provocador que incrementa el deseo de producción y de consumo, lo que exige la construcción y desconstrucción perpetua de ese objeto del deseo virtual, situación que implica un posicionamiento con respecto al producto creado, pues el cibernauta, en el chat, no solo adopta el objeto que le brinda posibilidades de identidad, sino que a su vez lo modifica cuando lo asume y lo hace parte de su propia producción creadora en la difusión de su yo, recreando a su vez usos innovadores, propios de la sociedad de consumo. Haciendo alusión a Pasquier (2005), en el mundo de la red, para ser uno mismo entre los otros, hay que ser y hacer como los otros, pues es la única manera de conseguir ser aceptado.

Esta aspiración de construir un lazo social no se basa en las pertenencias territoriales, ni en las relaciones institucionales, ni en las relaciones de poder, sino en la comunión, en el manejo del interés común, en el hecho de compartir el conocimiento de forma cooperativa y colaborativa en los procesos abiertos de la red: "El gusto por las comunidades virtuales se fundamenta en un ideal de relación humana desterritorializada, transversal, libre. Las comunidades virtuales son los motores, los actores, la vida diversa y sorprendente del universal por contacto" (Lévy, 2007, p. 103). 
Las prácticas cotidianas de uso, distribución, intercambio y consumo de los bienes inmateriales convierten a la red en lenguajes de acción, cuyo protagonista es la multitud de usuarios que proyectan y dan vida a sus pasiones. Por tanto,

Concebir, escribir y programar mundos virtuales requiere una síntesis de capacidades narrativas, estéticas y tecnológicas: desarrollar los conocimientos reunidos por el programador digital, el diseñador gráfico, el que testa el software, el escenógrafo, el animador, el técnico de sonido y de música. [...] Es una industria de jóvenes, reclutados en la cultura que ella misma ha creado, alimentándose principalmente de una reserva de gente joven fascinada por la tecnología y por su práctica incesante del juego (Moulier et al., 2004, p. 53).

Estos juegos mediáticos constituyen el mayor, mejor y más aceptado medio de ocio-mercado en la globalización actual. Así el mercado visto desde el trabajo inmaterial en la sociedad de la información se convierte en el eje articulador de las dimensiones e interacciones del mundo de la cibercultura, cuya dinámica invisibiliza la frontera entre consumidores y ciudadanos.

Ya no se trata de establecer diferencias, ya que la globalización actual ofrece un único mundo con multiversos posibles, donde proliferan creaciones de perfiles mayoritarios que brindan a los cibernautas posibilidades múltiples en la constitución de identidades y necesidades que son altamente satisfechas en la red de los chats, en este continuum de consumidores y consumidos, que evidencia "la necesidad casi terapéutica de apropiarse de las estupideces del presente, de devorar los objetos de nuestra dictadura del software, ya sean sonoros, musicales o audiovisuales para darles un nuevo sentido" (Moulier, et al., 2004, p. 83).

Por tanto, es importante hacer una relectura de la complejidad de los lenguajes de la cibercultura, que nos permita aproximarnos críticamente a ese entorno cognitivo de las actuales interacciones humanas y del mercantilismo que hay en concurso con los ordenadores; esta hiperconectividad, según parece, se ha convertido en una de las características medulares de la cibercultura. De hecho, la reproducción, ficciones, avatares y demás procesos de sentido que los sujetos dan a su entorno suceden a través de las tecnologías de la información y de la comunicación, en el Ilamado ciberespacio, que es:

El nuevo medio de comunicación que emerge de la interconexión mundial de los ordenadores. El término designa no solamente la infraestructura material de la comunicación numérica, sino también el oceánico universo de informaciones que contiene, así como los seres humanos que navegan por él y lo alimentan (Lévy, 2007, p. 5).

Con la producción innovadora de una sociedad que no repara en el tiempo, ni en el espacio, la creación intelectual no establece las diferencias entre el tiempo de trabajo y el tiempo del ocio o el lugar desde donde se diseñen los proyectos; simplemente es una sociedad de consumo, en la cual se tiene reloj pero no tiempo.

\section{DE LA ECONOMÍA POLÍTICA A LA CIBERCULTURA}

La economía política como concepto nació con Antoine de Montchrestien (2000), en 1615, a partir de la publicación de su texto Traité d'économie politique, y su importancia radicó en el mismo nacimiento de los estudios de las relaciones de producción, otrora entre los capitalistas y la burguesía y, sobre todo, entre proletarios y terratenientes (Cuevas, 2002). Su metodología y el desarrollo de sus principios teóricos producen un revelamiento de las leyes que rigen el comportamiento económico y abren el camino para el proceso de crecimiento de la ciencia económica. 
Este hecho es trascendental para iniciar el estudio de los modos de producción social, en concreto, de las relaciones económicas como un tipo de relación social que se enfoca específicamente en la relación de los hombres respecto de las cosas, mas no del hombre con las cosas.

Para tal efecto, Cataño (2009) ofrece una síntesis clara que ayudará a comprender este cambio de estado: se denomina teoría o enfoque clásico en economía a aquel conjunto de problemas, formas de apreciación y tesis que se derivan de un conjunto de trabajos que toman su inspiración original de las obras de pensadores como Adam Smith (1997) y David Ricardo (1984) (sin exclusividad, puesto que otros autores adherían a la misma corriente) y a ciertas ideas (no todas) de Karl Marx (1999). En el siglo XX, esta perspectiva tiene como uno de sus grandes momentos la obra crítica y positiva de Piero Sraffa (1960) y el movimiento analítico denominado neorricardianismo.

En efecto, el nacimiento de este enfoque en la economía gesta otra disciplina como la macroeconomía o política económica y, por supuesto, la reproducción de la misma; por tal motivo, reseñar por lo menos los gestores e ideas centrales de la economía política clásica permite centralizar la relación entre economía, capitalismo cognitivo y cibercultura con las dinámicas e improntas de las generaciones posmodernas. Este proceso es necesario como soporte teórico desde la historia económica de Smith hasta nuestro tiempo.

Así, los economistas clásicos, Smith (1997), Ricardo (1994), Mill (1978), Say (2001), Marx (1999), Maltus (2008), Sraffa (1960), desarrollan con parecida identidad conceptual, aunque con diferente y clara evolución unos de otros (metodológica y conceptual), la teoría del valor, de los precios y la distribución (salarios, ganancia y renta) hasta la acumulación del capital; por tal motivo, se hace importante e interesante el ejercicio de reconstruir someramente tales teorías y diferenciar su evolución (Cataño, 2009), lo que permitirá hacer una relación directa con la política económica en el mundo de bienes y servicios de la cibercultura.

\section{Apuntes sobre el enfoque real}

Una de las características de la economía política clásica es designarla como enfoque real; así, se está de entrada determinando una línea específica de análisis, sin ambigüedad. Por lo tanto, se designa el enfoque real, en términos de Cataño (2009), como aquel método que ha tratado de explicar, en un mundo de agentes y bienes, los fenómenos económicos de los cuales excluye el dinero y el Estado (economía del trueque), es decir, "el mercado por fuera del mercado".

Esta es una primera aproximación al mundo del ciberespacio, la relación entre economía y lenguaje, donde los agentes son virtuales aunque reales y los bienes no tienen precio, pero sí la interacción y la interactividad ${ }^{4}$. Esto también produce riqueza, pues la fuerza productiva es el conocimiento, es decir, la creación inmaterial. El valor de Facebook no está en la tierra, en los bienes materiales tangibles, sino en el ciberespacio como fuerza productiva donde la interacción se hace riqueza, lo que equivale a entender estos lenguajes de contradicción, desde la economía política hasta el capitalismo cognitivo; en palabras de Fumagalli:

El acto de consumo no es ya, por lo tanto, reducible a la adquisición de una mercancía material o de un servicio, tal como la ciencia económica nos ha enseñado tradicionalmente hasta ahora. En el capitalismo cognitivo, el acto de consumo es, al mismo tiempo, participación de la opinión pública, acto de comunicación y marketing en sí mismo (2010, p. 168).

El valor de los bienes, es decir, de la red o la interconectividad es mínimo; lo que la hace y la

4 Asumiendo la virtualidad en el entendido semiótico, donde lo real puede verse como virtual, real y actual (Greimas y Fontanille, 2002). 
fundamenta es la interacción; por eso, el exorbitante valor en dinero (también virtual en primera instancia) está representado en los internautas y sus horas de conexión. Es tan alto el nivel de interconexión e interacción que Twitter reduce el número de palabras para la interacción; asimismo, el chat utiliza una infinidad de lenguajes multimodales abreviados en tiempo récord, lo que hace que cambie en términos de la economía del signo la dinámica de la comunicación, pero la hace efectiva al estar dimensionada por un efecto de concisión, elemento fundamental para hacer una variable explicativa del fenómeno, esto determina que en el signo está representado el capital y los valores simbólicos cuyos efectos influyen permanentemente en el flujo del capital material y cognitivo de la sociedad global actual. Entonces:

Se reconoce ahí el trabajo del signo en su dimensión económica del equivalente general y de mediador obligado del intercambio. Por su función en la circulación de mercancías, el dinero es el signo único de un logos demiúrgico que actúa permanentemente de ruptura de contacto entre sus significantes y significados; discurso del capital que se nutre del desequilibrio de su referencial (Baudrillard, 1976, p. 11).

Tanto como lo expresaron los economistas clásicos, el método de trabajo de este enfoque (real) es simple, ya que el dinero no interviene en el proceso; sin embargo, las variables definidas por la economía política clásica son las mismas:

1. El mercado-precio. En este aspecto, todo el peso de la explicación recae en los agentes de producción (cibernautas) y en los bienes de consumo (mercado cognitivo).

2. El proceso (que es aceptado como tal) tiene un equilibrio; entonces, la interacción y la interactividad en la red determinan un equilibrio en la participación, en la rapidez de los intercambios, en la actualización y proyección de las necesidades, armando así las mismas dinámicas de mercado. El valor ya no es el intercambio de productos (Tricou, 2008), sino de subjetividades, teniendo como base las nuevas formas de visibilización social y cultural, con las diversas manifestaciones multimodales de la intercomunicación de las sociedades red, al construir y dinamizar otras maneras de producir comunicación e intervenir en los procesos que orientan el mundo global desde estos escenarios de poder (Castells, 2001). La teoría del equilibrio es, entonces, la forma clave para mantener la interacción y la interactividad; es lo que estructura una variación en la capacidad económica.

Si soy más rápido, tengo más capacidad de memoria o mi tecnología es de punta, entonces se entra en otro estado, pues el equilibrio se rompe. Hay reglas en la cuantificación de palabras, pero el sistema Gmail es el mismo para los dos; se tienen las mismas posibilidades, no importa si mi estrato social es alto o bajo. Lo que desajusta es la capacidad de navegación, la velocidad de interacción, es allí donde está el desequilibrio, pero el ajuste social de navegar estrecha las diferencias.

En el enfoque real, el dinero aparece como un mediador, que, para el caso, es la compra de los bienes (computadores, electrónica, conectividad, etc.), pero no hay una explicación racional de su aparición, lo que se convierte en un supuesto. No tengo dinero, pero tengo cuenta de correo electrónico; no tengo bienes como computador, pero interactúo en Facebook; no tengo página, pero tengo Twitter, es decir, hago parte de esa cadena de valor, por lo tanto existo.

Vale la pena destacar que la economía política altera este hecho trascendentalmente, lo que permite entender con mayor precisión la relación de la economía con la cultura. La producción de mercancías virtuales y su valor se producen a través de mercancías inmateriales; en la red, 
todo es cierto y posible, desde la interacción erótica humana hasta el cibersex, pues "la cultura abarca un conjunto de procesos sociales de significación o, de un modo más complejo, la cultura abarca un conjunto de procesos sociales de producción, circulación y consumo de significados de la vida social" (García, 2004, p. 34).

Estas sinergias y la convergencia con la comunicación ciberespacial están trazando nuevos escenarios emergentes e interactivos muy diferentes que, a su vez, fomentan cambios profundos tanto en la propia conceptualización de la sociedad del conocimiento, el lenguaje y la economía, como en la cadena de valor: producción, distribución, circulación y consumo. Por tanto, nos encontramos enfrentados con una serie de acciones sociales, conceptos y variables que se encuentran en la base de los cambios de la sociedad.

Así que, para adentrarnos y comprender este escenario multimodal, es necesario un acercamiento a las interrelaciones sociales que, evidentemente, se están modificando y al equilibrio que se está fracturando. Esto proporciona una perspectiva y unos valores integrales al análisis sobre las dinámicas que generan las comunicaciones multimediales y las tendencias que estas formas simbólicas abiertas aportan a la cibereconomía.

Dichas formas simbólicas son referencializadoras, es decir, son construcciones que representan algo, se refieren a algo, dicen algo sobre algo (McLellan, 1995) desde el punto de vista de la producción sociosemiótica. Asimismo, son objeto de unos procesos de valoración de sentido; por un lado, una valoración simbólica o valor que se les atribuye en cuanto a que son estimadas por los individuos que las producen o las reciben (yo-tú), es decir, en tanto que proporcionan sentido existencial de identidad social; y, por el otro, una valoración económica como mercancía que puede ser intercambiada en el mercado.
Ambas formas de valor tienen un carácter intencional-pragmático y convencional; las formas simbólicas intencionales, por una parte, son interacciones múltiples de carácter virtual de un sujeto de acción y están orientadas a un sujeto o a un grupo. El internauta crea o produce determinado valor en las redes sociales, el cual es objeto de intercambio o transferencia social o económica; por ejemplo, crea íconos, emoticones, memes, promueve identidades, crea subjetividades, produce conocimiento. Entonces, el cibernauta persigue determinados fines u objetivos, que logra expresándose a sí mismo y, a su vez, transmitiendo una red de significados aceptados y valorados en la cibersociedad que en la cadena de valor se determina como un producto de consumo, gracias a su distribución, circulación y uso. Por otra parte, las formas simbólicas convencionales son aquellas que aceptan la interpretación de las mismas por aquellos sujetos que las reciben, las comunican, las convalidan y las reproducen, convirtiéndose en un capital semiótico cibercultural que se universaliza y se sustenta en las redes sociales a partir de los lenguajes multimodales y multimediales.

\section{BIOECONOMÍA E INTERACCIÓN EN LA RED}

La importancia que cobra el cuerpo en las actuales relaciones económicas de la cibersociedad es toda una relación de interacción e interconexión de los nuevos espacios creados y valorados desde la cibercultura. El cuerpo, como acontecimiento espacial, se manifiesta en la percepción que construimos de los otros y la proyección que cada uno hace de sus avatares en el uso de las comunicaciones multimediales. Esta corporeidad nos sitúa espacialmente, pero no nos localiza en un solo lugar, es un cuerpo situado, no colocado allí; este cuerpo no está "dentro" de un espacio, conforma un espacio habitado, que pone a los sujetos en situación de frontera, de performancia frente al mundo. 
Por ello, pensar el cuerpo, desde la virtualidad del chat, abre la posibilidad de pensar la cibersociedad, a uno mismo y a los otros; lo que significa que al comprenderse a sí mismo y al mundo, en esta dinámica rizomática multimedial, el internauta se ve obligado a edificar los modos de subjetividad manifiesta, fundamentalmente, en el espacio sin tiempo donde "el mundo de la súper modernidad no tiene las medidas exactas de aquel en el cual creemos vivir, pues vivimos en un mundo que no hemos aprendido a mirar todavía. Tenemos que aprender de nuevo a pensar el espacio" (Augé, 2000, p. 42).

Este "aprender de nuevo a pensar el espacio" hace que esta vivencia cibercultural nos confronte con un cuerpo que es fundamentalmente un espacio expresivo, cuya función primordial se da en la dinámica de la subjetividad corporal que se manifiesta en los múltiples lenguajes semióticos; entonces, este cuerpo que porta se construye y reconstruye en un espacio de simulación cuya "percepción", a manera de Merleau-Ponty (1975), no es personal, ni tampoco interpersonal, sino que se da siempre de manera subjetiva e intersubjetiva.

Al entender la espacialidad como una forma de ser, de pensar y de actuar en el mundo global actual, el ciberespacio se convierte en la vivencia corporal del mundo como derrotero de la cibercultura; el espacio digital, al carecer de distancias geográficas o "corporales", deja atrás el ritmo establecido en la modernidad, con respecto al tiempo y al espacio, para focalizar el ritmo sincrónico, veloz y fugaz en la cultura mediática de las TIC.

En concordancia con lo anterior, Bauman (2003) afirma que el espacio se ha separado del cuerpo y la percepción del tiempo, al igual que la del espacio, se ha transformado. En los espacios dimensionados por la cibercultura, las fronteras desaparecieron; el tiempo y el espacio se construyen como un hecho instantáneo, en el presente, en el ahora. Así, establece una especie de clasificación de los espacios como lugar de encuentro y de interacción de los sujetos: los espacios o lugares émicos (espacio inhóspito de prohibición de contacto físico); los espacios fágicos ( es la inclusión de las masas a la sociedad de consumo); los no espacios (un lugar provisto para el despojo de las expresiones simbólicas de la identidad); $y$, por último, los espacios vacíos (espacios en que se pierden las seguridades modernas para el sujeto, espacios invisibles a nuestra realidad, sin referente inmediato).

Es precisamente en estos espacios desprovistos de intimidad en los que se da la interacción y la interactividad de los sujetos en la red. Aquí, la economía política, cognitiva y cultural adquiere la capacidad máxima para multiplicarse y establecer un sinnúmero de construcciones simbólicas de subjetividades e identidades, a partir de un sistema trazado por la sociedad de consumo en red, con un mercado, producto del instante, que crea valor y reproduce todas las instancias del trabajo, las ganancias y demás variables económicas, así como otros vínculos personales, en los que la durabilidad de las relaciones interpersonales no es importante; solo el producto instantáneo importa, no el sujeto creador, ni los vínculos afectivos.

Entonces, las tecnologías de la cibercultura, al tener el poder de construir mundos virtuales, poseen las características de carecer de referencias espaciales y temporales; allí todo puede ser alcanzado sin límite alguno, lo que genera modelos de identidad que carecen de referencia corporal, pero que, según Sibilia (2009), responden a una conciencia no humana, sino cibernética, lo que permite crear modelos identitarios ad infinitum.

Este juego de subjetividades y de creación de avatares $^{5}$ ciberculturales, donde los cuerpos se transforman sin darse cuenta, no tiene límites, pues no solo es atemporal y acorporal, sino que

5 Los avatares son simulaciones (virtuales) creadas por los sujetos nómadas a partir de sus subjetividades. Esta proyección de la corporeidad nos sitúa en un espacio-red de múltiples posibilidades de ubicuidad. Este avatar es la representación de sentido de un sujeto de acción que configura su cuerpo en una situación de frontera que le permite todo tipo de conexiones. El avatar habla por el cuerpo. 
no necesita corporalizarse, ya que la pérdida de contacto referencial no impide su producción: "la tecnociencia contemporánea parece realmente dispuesta a redefinir todas las fronteras y todas las leyes, subvirtiendo la antigua prioridad de lo orgánico sobre lo tecnológico y tratando a los seres humanos preexistentes como materia prima manipulable" (Sibilia, 2009, p. 53). Realmente, todo es posible para deshacerse de ese cuerpo físico, con un número infinito de programas de simulación. Definitivamente, "el cuerpo consumidor (o del consumido) es 'autotélico', ya que constituye por sí mismo su propia finalidad y valor. En la sociedad de consumidores resulta ser, además, el valor definitivo" (Bauman, 2006, p. 123).

Estas prácticas de la "sociedad moderna líquida" que "disuelven" el espacio y el cuerpo van provocando el cambio de las categorías demarcadas en la modernidad, como adentro y afuera, público y privado, interior y exterior, "extimidad" e intimidad, cuya dimensión en el mundo virtual ejerce cierto tipo de imposibilidad de pensarse, ya que carecen del espacio corporal, como sustento objetivo, por cuanto en las redes sociales, particularmente en el chat (caso que nos ocupa), lo público comienza a pensarse como un espacio ocupado por muchos y ajeno a la vez.

Es así como el cuerpo intenta construir espacios-red de conexiones múltiples corporizados para reconocerse en ellos, generando adherencias que sutilmente fueron imbricadas en el espacio alterno, esporádico y continúo del internet, regido por la sociedad de consumo, en un afán por establecer un mercado inmaterial de bienes y servicios que le da cabida a todos los sujetos internautas, estipulando con ello que el único valor simbólico adquirido por los cuerpos, en nuestra cultura actual, sea el de mercancía (Sibilia, $2008)^{6}$.

6 Sibilia (2008) considera que la mayor vidriera de ese mercado son los blogs y las redes sociales donde la intimidad se espectaculariza y se hace un culto del cuerpo-mercancía.

\section{CIBERCULTURA, CHAT Y SOCIEDAD DE CONSUMO}

De hecho, el sujeto de la cibercultura frente a la sociedad de consumo se incorpora al mercado de oferta y demanda, ya sea como creador o consumidor de bienes inmateriales: "el sujeto encarnado participa de una dinámica creativa de sí mismo y del mundo con el que está en permanente inter-cambio" (Najmanovich, 2001, p. 16); vive, se organiza y piensa en torno al consumo, lo que conlleva a la pérdida de la subjetivación en la continua búsqueda de nuevas formas de ser, de pensar y de sentir. Esta capacidad de transformación se da a través de las variadas formas de interpretación de los lenguajes, debido a que:

Interpretamos porque no hay transparencia del significado, porque siempre nos enfrentamos a dimensiones del sentido, porque este es contingente, mediado, diverso y divergente, porque constituye una construcción modalizada del mundo; en fin, porque el lenguaje es plástico y elástico y ejerce múltiples mediaciones en la cultura (Cárdenas, McNeil y Malaver, 2012, p. 153).

De este modo, la afirmación de la corporalidad del sujeto conduce a repensar el espacio clásico, habitado por el sujeto moderno, en otras dimensiones (espacio-red) que abarquen la multitud de espacios imbricados en las redes de la cibersociedad. Esto implica trabajo colectivo, interacción, relación y transformación de los espacios y los entornos cognitivos tradicionales, donde se le da espacio e importancia a nuestra corporalidad, la que sin lugar a duda, en palabras de Najmanovich (2001), "determina un campo de afectación y la clase de interacciones y de transformaciones posibles" (p. 19).

Estos procesos se dan en las configuraciones de sentidos que reconocen y recrean los sujetos y que fácilmente se refrendan en el mundo virtual a través de sus avatares y mundos posibles. Esta posibilidad de ser otro en una multiplicidad 
de espacios permite que el cibernauta se modifique a sí mismo o que sea modificado por los otros internautas a partir de la interacción e interactividad mediada en los chats. Esto determina a un sujeto de acción, de experiencia, de conocimiento que afecta y define su modo de ser, estilos de vida, sus deseos y sus prácticas de consumo desde la cibercultura, ya que toda representación del sujeto es una construcción mediada por el orden sociocultural.

Entonces, mientras que en la modernidad el estereotipo de subjetividad es unificado y moldeado a imagen y semejanza de las instituciones que manejan el poder, la familia, el Estado, la economía, la constitución de las subjetividades, en la actual sociedad en red involucra la acción plena de la vida de los sujetos como práctica mediática.

Por lo tanto, la constitución de subjetividades en el escenario de los entornos cognitivos multimediales y multimodales del chat público establece unos modos propios de creación y conformación de los mercados inmateriales, a través de los lenguajes semióticos que dan vida a las identidades y a los modos de ser y hacer, en la cibercultura proyectada en la era del capitalismo cognitivo, cuyo eje es la construcción colectiva de conocimientos en red, que a su vez deviene en mercancía, la cual circula en la cadena de valor donde el "producto" se distribuye, se consume y se vende. De hecho, esta venta de identidades, de subjetividades, de cuerpos, así como de arte y demás productos que se hacen forzosa y simbólicamente necesarios para la sociedad, se convierte en la propiedad intelectual de algunas redes de poder ciber.

En este orden de ideas, la condición de la cibersociedad actual constituye una búsqueda de espacios plurales y fluidos, donde el sujeto marca su propio trayecto y elige su motor de búsqueda, para lograr su espectacularidad y el ejercicio de venta y consumo. Esta frenética carrera induce al cibernauta a contemplar una serie de giros de la subjetividad, mediados por los giros lingüísticos, discursivos, semióticos, narrativos, hermenéuticos; manifestaciones propias del sujeto, a través de sus actitudes, posiciones, posturas, puntos de vista y aspectos que hacen del ser un ser-sujeto de acción.

Entonces, el sujeto no es una entidad estática, sino una sinergia de realidades que se construye de acuerdo con las condiciones y las posibilidades que brinda el mundo cibercultural. De hecho, en el mundo global actual, la realidad se crea y recrea desde los lenguajes y la transdisciplina: una relación que no obedece a los principios de la lógica aristotélica (principio de identidad, de no contradicción y de tercero excluido), pues los lenguajes son multimodales y divergentes como el hombre mismo y, lo que es innegable, marcan un derrotero excepcional en las formas de vida actuales, en las que la acción del sujeto internauta se globaliza a través de una pantalla, donde:

(...) nunca llegamos a saber, a pesar de ser compañeros de comunicación, qué es lo que está tras la pantalla y lo mismo pasa para el propio sujeto interesado (el sujeto no sabe lo que está tras la pantalla de su propia [auto] conciencia, qué clase de cosa es él en lo Real), la autoconciencia es una pantalla de superficie que produce el efecto de profundidad de una dimensión que está por debajo de ella. (...) el propio efecto de "profundidad" de una persona se disuelve (Žižek, 2006, p. 140).

La correspondencia con las redes sociales hace que los sujetos construyan su conocimiento del mundo a partir de múltiples narraciones y puntos de vista que fortalecen los procesos heurísticos y epistemológicos de las ciencias, que a su vez coadyuvan en la construcción de una sociedad diversa y pluricultural, en tanto que:

El sujeto al actuar sobre la realidad y conocerla, fija puntos de vista y aprende a compartir y a conciliar estrategias para construir la visión 
tridimensional mundo/yo/otro, transformándose en sujeto histórico social de conocimiento y de discurso; pero además en sujeto modal, con capacidad para optar de manera libre, razonada y argumentada frente al mundo vivido (Cárdenas, 2001, p. 77).

Desde estas perspectivas la concepción fija y univoca del sujeto se reemplaza por la búsqueda de espacios y narrativas plurales (múltiples visiones como narradores existen en un espacio fragmentado, descorporeizado y fugaz); esta modalidad y nuevas visiones del mundo son el prototipo de una sociedad globalizada y tecnologizada, la cibersociedad. Esta dinámica dada en el marco de la cibercultura establece un juego de relaciones y roles que toman vida propia con base en las interacciones subjetivas propias de la tecnologización; pues:

Los individuos hipermodernos están a la vez más informados y más desestructurados, son más adultos y más inestables, están menos ideologizados y son más deudores de las modas, son más abiertos y más influenciables, más críticos y más superficiales, más escépticos y menos profundos (Lipovetsky, 2006, p. 29).

Desde este panorama, el mundo virtual como mercado de bienes y servicios, donde la interacción es más que una cultura o una forma simbólica de significación y representación de la sociedad, es, en términos de Smith (1997), un valor definido por los precios y la distribución. Su utilidad (valor de uso) y su valor de cambio están definidos en otro tiempo, otro espacio y otras dinámicas, pero igualmente son una forma de representación económica sociocultural.

En esta despersonalización el cibernauta,al verse y sentirse inmerso en estas necesidades creadas, se evapora en los productos de los mercados y se transforma en una cadena de valor de los poderes de los mercados financieros, de tal forma que:

El universo del consumo y la comunicación de masas se presentan como una fantasía un mundo de seducción y de movimiento incesante cuyo modelo no es otro que el sistema de la moda. No hay ya, como en las sociedades tradicionales, repetición de modelos del pasado sino todo lo contrario, novedad y tentación sistemáticas, como norma y organización del presente (Lipovetsky, 2006, p. 63).

Así, detrás de la cibercultura y el chat como forma de interacción semiótica está el mundo de bienes y servicios, el amplio mercado tecnológico de equipos, artículos, programas, software, accesorios, etc. La variación tecnológica crea un enorme mundo de valores y riqueza; los programas, los equipos y los aparatos multimediales generan dependencia y necesidades obligadas en una fuerte dinámica que ejerce la sociedad de consumo, donde todo es necesario para la interacción social en red.

Por lo tanto, las relaciones, las producciones y los procesos de significación suceden a través de las tecnologías de la información y la comunicación, tejidos en los lenguajes ciberculturales en todas sus dimensiones semióticas. En este punto, el capitalismo cognitivo, visto como la producción infinita de información, conocimientos y prácticas simbólicas, se convierte en foco primordial de los estilos de vida de los cibernautas.

La gama de bienes y servicios abre una gran posibilidad de acumulación de capital; ofertas y demandas que dependen de la capacidad de innovación, de la competitividad, de la agilidad en la socialización y visibilización en la red, de sus estrategias multimodales y de la creatividad de los cibernautas en la promoción de mercancías inmateriales, producidas a través de las nuevas tecnologías, el diseño y el marketing; que, sin duda, son muy bien manejados y 
mercantilizados desde las subjetividades y necesidades del otro, a partir de lo cual se subsume la vida entera en función del mercado.

Así el mercado se convierte en un elemento básico y orientador de la vida social, igualmente si no se trabaja también se consume; en tanto que la intimidad, la familia, la amistad, la recreación son una fortaleza en la producción y reproducción del capital, cuyos pilares son los afectos, las emociones y las creencias como su principal factor productivo.

Aquí los cibernautas se sienten y son partícipes de este mundo de ficción virtual, ya sea como consumidores o como creadores de vías de consumo; de todas formas, el producto simbólico que emerge de esta red-ada, cobra un alto "precio" y un alto significado en ese espacio virtual y en la vida cotidiana de los sujetos, quienes se difuminan en la infinita cadena de oferta y demanda de la sociedad actual de consumo, en la que el conocimiento se ha puesto al nivel de la producción.

\section{CONCLUSIONES}

En el contexto que nos interesa, estos preceptos del objeto de estudio de la economía política ayudan a entender, por una parte, cómo se dan las relaciones de producción en la esfera de la nube (almacenamiento y procesamiento masivo de datos en servidores de internet) y la interacción electrónica en las sociedades del conocimiento y la información; y, por otra parte, cómo las implicaciones epistemológicas de otras formas y relaciones de producción transforman las dinámicas socioculturales.

A partir de la web 2.0, la participación colectiva de los usuarios establece mecanismos de alto nivel de interacción; esta comunidad de usuarios utiliza los servicios multimedia para estar interconectados en las redes sociales. Desde estas interacciones multimodales y multimediales se logra un intercambio ágil de la información y una colaboración masiva en la creación de toda clase de contenidos, este tipo de servicios en red se valen de la inteligencia colectiva como fuerza de producción inmaterial del capitalismo cognitivo.

Por ello, en la web 2.0 se puede entender la "relación social" como cualquier intercambio de subjetividades (sentidos, sentimientos, pasiones, emociones, conocimientos, datos, corporalidades) que se teje (red de sentidos) entre un colectivo de personas virtualmente conectadas. Así las cosas, dispositivos como el chat, el foro o el correo electrónico generan nuevos proceso de constitución de subjetividades.

Esta a su vez, de forma dialéctica, se ha transformado (web 3.0 y 4.0) por efecto de la imbricación de otras posibilidades narrativas, de nuevas tensiones en la producción de sentido y, sobre todo, por la emergencia de nuevas formas y ocurrencias de suplir las necesidades creadas desde el capitalismo cognitivo, generado a partir de las TIC; estas necesidades consumistas, humanas, sociales y cotidianas son valoradas y suplidas de manera inmediata a través de la interacción e intercomunicación en la red. Hablar de las redes 3.0 y 4.0 significa un avance muy superior en la información y en la comunicación, lo que muestra una evolución muy marcada en los progresos de las telecomunicaciones.

La web 3.0 es una red semántica óptima por su fácil y rápido acceso al intercambio e interacción de la información y la participación en redes sociales, situación que facilita la movilidad de los espacios red de los usuarios. El sistema operativo simula el cerebro a partir de la utilización de la inteligencia artificial, con lo que pone énfasis en el análisis y capacidad de procesamiento de las ideas a partir de los metadatos semánticos y la información producida por los usuarios (inteligencia colectiva), de tal manera que el capitalismo cognitivo mediado por la web, al lograr anclar al cibernauta como entidad colectiva y productiva se convierte en el amo de la comunicación y la información, en 
un mudo que, sin lugar a dudas, se construye en red.

La web 4.0, denominada red móvil, funciona a partir de las comunicaciones inalámbricas, lo que quiere decir que tanto personas como objetos se comunican en cualquier momento y desde cualquier lugar del mundo físico o virtual. A este acceso de un mayor número de objetos en la red se deben sumar los contenidos generados por los usuarios, con lo cual se dinamiza la construcción de otro nivel de análisis; aquí el sujeto, en sus prácticas ciberculturales, es un sujeto de acción, pasión y transformación.

De acuerdo con lo dicho, las redes sociales son la representación de las relaciones sociales validadas y configuradas como "reales" en la vida cotidiana, pero pasadas por el filtro de lo que los internautas simbolizan y proyectan; por lo tanto, es una idealización de lo que se quiere ser, hacer y tener, situación que se evidencia en los perfiles creados por los usuarios como sustituto de su identidad.

La presencia de este nuevo sistema multimodal y multimedial de información y comunicación, más que ser una transformación de la práctica lectoescritora, es la descripción del cambio en el sentido que los sujetos dan a su propia existencia y a su forma de narrar, intercambiar y comprender la experiencia humana (Virilio, 1997).

Se trata de entender, entonces, cómo la cibercultura, en el sentido de la economía política y el capitalismo cognitivo, construye las relaciones en cadena a partir de otras fuentes de interacción, en cuya cultura simbólica se configura una amplia gama de signos y símbolos que formalizan otras formas de producción inmaterial específica; el verdadero valor del trabajo implica unas nuevas relaciones sociales de producción que, en este caso, hacen parte de una cultura cuyo capital simbólico de bienes inmateriales está constituidos desde la virtualidad:

Estos poderes económicos que circulan en los ambientes ciberculturales y ciberespaciales vistos desde la virtualidad, la economía y la cultura tienen actores determinantes frente a las políticas informáticas, como son el Estado, la empresa privada y las comunidades consumidoras, quienes validan el valor de uso y de cambio que se confiere a determinado signo y cuyo valor simbólico en la red sirve de puente y de conexión con la vida, con la memoria, con la experiencia, con el contexto de los internautas. En la medida en que cada signo adquiere valor y significación, permite el intercambio sociocultural, ya sea, virtual, lingüístico, económico o social.

De ahí la importancia de entender cómo se manejan las relaciones simbólicas en una red de mercado y demanda de bienes inmateriales, donde proliferan las múltiples identidades y donde el cibernauta está preso en un sinfín de ofertas y demandas que revelan la dependencia de los medios, de las actividades online.

La producción del capitalismo cognitivo que se está consumiendo en la actual economía globalizada hace que las grandes multinacionales mediáticas ejerzan un poder monopolizador sobre el capital simbólico creado en el espacio-red. Dicha producción, distribución y consumo de los bienes inmateriales, a través de internet, conforman un tejido rizomático social que configura otras dinámicas de trabajo colectivo, cuyos valores dominantes no son otra cosa que la promoción múltiple de identidades corpóreas, aprovechable para la producción exacerbada de los actuales modos de vida.

En el capitalismo cognitivo y en la sociedad-red, el sujeto a través del uso de los lenguajes multimodales genera otras formas de sentido y de construcción de realidades, que edifican su subjetividad, sus deseos, sus relaciones, su accionar frente a lo que la sociedad de consumo ha modelado.

\section{RECONOCIMIENTOS}

Este artículo hace parte de la investigación doctoral "Configuración sociosemiótica del chat: una 
visión multimodal", del programa de Doctorado en Lenguaje y Cultura, de la Universidad Pedagógica y Tecnológica de Colombia, en la línea de investigación lenguaje, sociedad y cultura. Por otra parte, esta línea confluye con la del grupo de investigación Comunicación, Educación y Cultura de la Facultad de Ciencias y Educación de la Universidad Distrital Francisco José de Caldas, grupo avalado por Colciencias.

\section{REFERENCIAS}

Augé, M. (2000). Los "no lugares" espacios del anonimato. Una antropología de la sobremodernidad. Barcelona: Gedisa.

Bauman, Z. (2006). Vida líquida. Barcelona: Paidós.

Bauman, Z. (2003). Comunidad, en busca de seguridad en un mundo hostil. España: Siglo XXI.

Baudrillard, J. (1976). La génesis ideológica de las necesidades. Barcelona: Anagrama.

Bell, D. (1991). El advenimiento de la sociedad post-industrial. Un intento de prognosis social. Madrid: Editorial Alianza Universidad.

Cárdenas, A., McNeil, F., y Malaver, R. (Julio-diciembre de 2012). Comprensión, sentido y pedagogía. Colombian Applied Linguistics Journal, 14(2), 146-162.

Cárdenas, A. (Enero-julio de 2001). Implicación, inferencias y competencias de interpretación. Folios, (13), 69-81.

Castells, M. (2001). La galaxia internet. Reflexiones sobre internet, empresa y sociedad. Madrid: Areté.

Cataño, J. (2009). Lecciones de economía marxista: mercados, precios y dinero desde un enfoque heterodoxo. Bogotá: Universidad Nacional de Colombia.

Cuevas, H. (2002). Estudios de economía política. Bogotá: Universidad Nacional.

Featherstone, M. (2000). Post-bodies, aging and virtual reality. En D. Bell y B. Kennedy (eds.), Cybercultures reader (p. 609). Londres y Nueva York: Routledge.

García, C. (2004). Diferentes, desiguales y desconectados. Barcelona: Gedisa.
Greimas A. J., y Fontanille, J. (2002). Semiótica de las pasiones. De los estados de cosas a los estados de ánimo. México: Siglo XXI.

Lévy, P. (2007). Cibercultura. La cultura de la sociedad digital. España: Anthropos.

Lipovetsky, G., y Charles, S. (2006). Los tiempos hipermodernos. Barcelona: Anagrama.

Maltus, R. (2008). Los principios de economía política. Madrid: Instituto de Estudios Fiscales.

Marx, K. (1999). Marx y la teoría económica actual. Ensayos de Economía, 10(16), 89-120.

McLellan, D. (1995). Ideology. Great Britain: University of Minnesota Press.

Merleau-Ponty, M. (1975). Fenomenología de la percepción. Barcelona: Ed. Península.

Mill, J. S. (1978). Principios de economía política. México: Fondo de Cultura Económica.

Montchrestien, A., y Brentano T, (2000). Traité de l'économie politique. Paris: Rivière.

Moulier, Y., Corsani, A., y Lazzarato, M. (2004). Capitalismo cognitivo. Propiedad intelectual y creación colectiva. Madrid: Editorial Traficantes de Sueños.

Najmanovich, D. (2001). El sujeto encarnado: Límites, devenir e incompletud. Recuperado de http://fac. org.ar/1/docencia/foros/cardtran/gral/sujeto $\% 20$ encarnado.htm.

Pasquier, D. (2005). Cultures Lycéennes. La tyranie de la majorité. París: Ediciones Autrement.

Ricardo, D. (1984). Principios de economía política y tributación. México: FCE.

Ricardo, D. (2001). Ricardo o el perfeccionamiento de la economía política clásica. México: FCE.

Saussure, F. (1985). Curso de lingüística general. Barcelona: Editorial Planeta.

Say, J B. (2001). Tratado de economía política. España: FCE.

Sgraffa, P. (1960). Producción de mercancías por medio de mercancías. Preludio a una crítica de economía política. Barcelona: Oikos-tau.

Sibilia, P. (2008). La intimidad como espectáculo. Buenos Aires: FCE.

Sibilia, P. (2009). El hombre postorgánico: cuerpo, subjetividad y tecnologías. Buenos Aires: FCE. 
Smith, A. (1997). La riqueza de las naciones, Smith y el giro de la economía política clásica. México: FCE.

Tricou, F. (2008). Versión real y versión monetaria de una economía de mercado artesanal. Lecturas de Economía, 68, 175-193.
Virilio, P. (1997). El cibermundo, la política de lo peor. Madrid: Cátedra.

Žižek, S. (2006). Órganos sin cuerpo. Sobre Deleuze y consecuencias. Trad. Antonio Gimeno Cuspinera. Valencia: Pretextos.

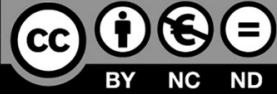

